\title{
Embodied energy and its impact on architectural decisions
}

\author{
H. J. Holtzhausen \\ Faculty of Art, Design and Architecture, University of Johannesburg, \\ South Africa
}

\begin{abstract}
When sustainability is the driving force in the creation of a building, specifiers and architects need additional knowledge to assist them in making decisions about the choice of building materials and the way in which they are used. This article brings together embodied energy values in different materials with a view to adjusting decisions made by specifiers and architects that will have the effect of extending the life of a building and increasing its environmental value. Embodied energy is the total non-renewable energy that goes into the manufacture of a material and plays a large role in the choice of building materials. It is an important factor to consider when assessing the life cycle of a building and it relates directly to the sustainability of the built environment.

This paper examines embodied energy of the most dominant building materials/components such as cement, steel, and aluminium and assesses the source of the largest consumption of energy in the life cycle of the building material.

Data is drawn from a variety of sources, mostly from the manufacturers' data of the specific building materials to assess the biggest cause of energy consumption. Previously scattered information known in specific industries is brought together for the building industry. The compilation of information provided will assist in the making of informed decisions when considering a sustainable approach to the life cycle of a building.

To ignore the importance of embodied energy when doing a Life Cycle Assessment, the building's cost in the end could become very expensive because of the impact of maintenance and differential durability. With a little more planning to consider the life cycle and embodied energy of the materials used at the initial stage of creating a building, it could become far more sustainable.

Keywords: embodied energy, Life Cycle Assessment.
\end{abstract}




\section{Introduction}

Currently the built environment is a huge consumer of depletable energy resources and is altering the planet's environment in an irreversible way. Over the span of a building's life the operational energy rather than the embodied energy of a building is the largest energy consumer. This is mostly due to the current culture among architects and their clients who opt for technological or aesthetic monuments while ignoring issues pertaining to the sustainability of a building. Fortunately, this culture is slowly moving towards more responsible architecture that starts to consider the impact of the built environment on the global environment. As buildings become more energy efficient with the correct design philosophies, a closer look is needed at the embodied energy of a building and the materials used in constructing, operating and maintaining a building.

\section{Measuring embodied energy}

Embodied energy is divided into two main areas, namely Initial embodied energy and Recurring embodied energy. Initial embodied energy is nonrenewable energy consumed in the process from the acquisition of raw materials to the construction of the building. For example, a steel window frame will have the initial embodied energy that is derived from the mining of the ore, its melting and processing, the transportation of the steel to the window manufacturing plant, the manufacturing of the window frame and its transport to the building site. Initial embodied energy is influenced by the source and type of building materials and the nature of the building. Recurring embodied energy is nonrenewable energy consumed to maintain, repair, restore, refurbish or replace materials, components or systems during the building's life span For example, a window frame that is not sufficiently protected from rust might have to be replaced, or painted. Recurring embodied energy is influenced by the durability and maintenance of building materials, systems and components installed in the building, and the life span of the building. As the life span of a building increases, the operating energy significantly increases and the initial embodied energy of the building becomes insignificant in comparison.

The associated environmental implications of embodied energy such as resource depletion, the production of greenhouse gases, maintenance of biodiversity, and environmental degradation are embedded in the measurement of embodied energy. The energy is expressed in units of Mega Joules (MJ) or Giga Joules (GJ) per unit of weight (Kilogram or tonne) or area (square meter). The process of calculating embodied energy is very complex and a variety of data sources are used considering the complexity of such calculations. Factors such as geographical location technology employed in the manufacturing process and methods of manufacture play a large role on the embodied energy of materials. 


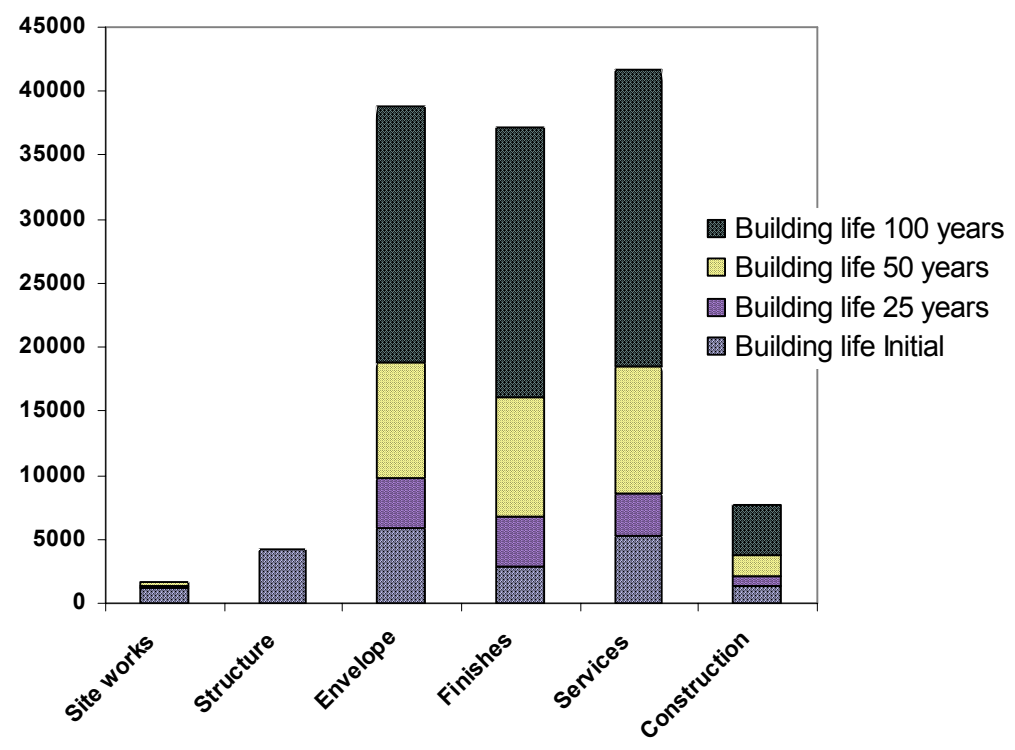

Figure 1: Comparison of initial to recurring embodied energy for a timber structure building over a 100-year lifespan (Cole and Kernan [3]).

\section{Embodied energy in major building materials}

A closer look at the industry of Building Materials suppliers is necessary to understand the impact of construction materials on the environment, and specifically how the manufacturing of building materials cause depletion of natural resources. In this instance aspects such as externalities will not be examined. The Australian CSIRO (Scientific and Industrial Research Organization) states that the energy consumed in the manufacturing of building materials are highly correlated to $\mathrm{CO}_{2}$ (Carbon Dioxide) emissions. An average of 0.098 tonnes of $\mathrm{CO}_{2}$ per GJ of embodied energy is produced. Cement and Aluminium are of the highest $\mathrm{CO}_{2}$ producing materials. A large amount of $\mathrm{CO}_{2}$ is produced with the transport and processing of building materials. The major building materials the author wishes to discuss more are; cement, aluminium and steel.

\subsection{Cement}

Cement is an integral part of concrete and is used in tiling and plastering. Of the building materials available, cement is one of the biggest contributers of greenhouse gas pollutants.

The production of cement consists of the combining, blending and grinding together of raw materials (limestone, clay and sand) to provide the basic 
ingredients of cement, i.e. calcium, silica, alumina and iron components. After grinding the materials are heated to very high temperatures to create marblesized bits of clinker that (once cooled) is ground with a small amount of gypsum into cement powder.

Table 1: $\quad$ Embodied energy of building materials Canadian Architect [8] and Centre for building performance research [2].

\begin{tabular}{|l|r|r|}
\hline \multicolumn{3}{|c|}{ Embodied Energy } \\
\hline & $\mathrm{MJ} / \mathrm{kg}$ & $\mathrm{MJ} / \mathrm{m}^{3}$ \\
\hline Aggregate & 0.10 & 150 \\
\hline Stone (local) & 0.79 & 2030 \\
\hline Concrete block & 0.94 & 2350 \\
\hline Concrete (30Mpa) & 1.30 & 3180 \\
\hline Concrete precast & 2.00 & 2780 \\
\hline Brick & 2.50 & 5170 \\
\hline Cellulose insulation & 3.30 & 112 \\
\hline Steel (recycled) & 8.90 & 37210 \\
\hline Steel & 32.00 & 251200 \\
\hline Plywood & 10.40 & 5720 \\
\hline Glass & 15.90 & 37550 \\
\hline Fibreglass insulation & 30.30 & 970 \\
\hline Zinc & 51.00 & 371280 \\
\hline Brass & 62.00 & 519560 \\
\hline PVC & 70.00 & 93620 \\
\hline Copper & 70.60 & 631164 \\
\hline Paint & 93.30 & 117500 \\
\hline Linoleum & 116.00 & 150930 \\
\hline Polystyrene Insulation & 117.00 & 3770 \\
\hline Carpet (synthetic) & 148.00 & 84900 \\
\hline Aluminium (recycled) & 8.10 & 21870 \\
\hline Aluminium & 227.00 & 515700 \\
\hline
\end{tabular}

The energy consumed in the cement manufacturing process is largely due to the high temperatures at which the limestone, clay and sand are heated to create clinker (up to $1870^{\circ} \mathrm{C}$ ). The other processes, such as quarrying before the heating and grinding after the heating, are not such huge energy consumers.

According to the Portland Cement Association [9], the reduction of environmental impact of the cement manufacturing process can be achieved by using larger quantities of limestone and recycling of cement kiln dust. Mention is made of the use of waste-derived fuels in the heating process. The use of stateof-the-art equipment and new technologies could reduce the high energy demand of cement production. Currently cement production accounts for $0.33 \%$ of the $\mathrm{CO}_{2}$ emissions of the United States as opposed to transportation's $27 \%$. 


\subsection{Steel}

Due to its weight, steel is high in embodied energy when it comes to transporting it over large distances. Yet it has structural qualities that makes it a very popular building world wide. It is $100 \%$ recyclable and when it is used in construction it can be designed for easy dismantling and re-use of standard steel sections.

Some byproducts of the steel manufacturing process are used in the construction industry such as blast furnace slag (the scum from molten metal that is separated in smelting), used as roadstone, and steelmaking slags that are ground and used in cement, or crushed and used as a concrete aggregate.

The process of manufacturing steel is extremely energy intensive and consists of a number of procedures. Molten iron is produced in the blast furnace where iron ore, coke, sinter and flux is heated up to $900^{\circ} \mathrm{C}$. The blast furnace is used continuously for about 10 years. Coke is produced by heating blended coal, carbonizing it. Byproducts of coke such as tar and benzole are extracted for other uses. Steel is produced by oxidizing the carbon and other unwanted elements in the iron in furnaces to purify the iron. This process is done at very high temperatures and uses a large amount of energy. The arcing process alone (to melt steel scrap with an arc created by passing an electric current through electrodes in the lid of a furnace) uses enough energy to power a town with a population of 100000 (Corus Construction Centre [4]).

The most effective way of reducing the environmental impact of steel in construction is to design for disassembly (Catalli and Williams [1]), and re-use of existing structural steel members. Transport costs can be cut down by sourcing steel from local producers.

\subsection{Aluminium}

A material of high paradox, aluminium has an extremely high embodied energy when initially extracted and manufactured. However, its recycling is relatively cheap and easy and by weight has the embodied energy comparable to that of particle board $(8.00 \mathrm{MJ} / \mathrm{kg})$.

Primary aluminium production has large scale negative impacts on the environment. The process starts with the mining of Bauxite which is followed by refining, smelting and finally modelling. Alumina refining uses on average $75 \mathrm{~kg}$ of caustic soda and $48 \mathrm{~kg}$ of lime per metric tonne of alumina. The fuel consumption and energy consumed in the manufacturing of lime and caustic soda supplementary materials are responsible for $991 \mathrm{~kg}$ of $\mathrm{CO}_{2}$ equivalents per metric tonne of alumina. Once used as a building material, Aluminium has a very long lifespan. It is one of the most durable products on the market, and highly recyclable. The recycling Aluminium involves smelting scrap Aluminium after screening it for ferrous materials by passing it through large magnets. Once smelted, it is cast or processed. As shown in Table 2, the recycling of Aluminium allows for large savings on the production of Greenhouse Gases. 
Table 2: The $\mathrm{CO}_{2}$ savings per tonne of aluminium recycled (International Aluminium Institute [7]).

\begin{tabular}{|l|l|l|l|l|}
\hline Aluminium Used & $\begin{array}{l}\text { All } \\
\text { Primary }\end{array}$ & $\begin{array}{l}30 \% \\
\text { recycled }\end{array}$ & $\begin{array}{l}60 \% \\
\text { recycled }\end{array}$ & $\begin{array}{l}95 \% \\
\text { recycled }\end{array}$ \\
\hline $\begin{array}{l}\text { Tonnes } \mathrm{CO}_{2} \text { equivalents } \\
\text { saved per tonne of } \\
\text { aluminium }\end{array}$ & 13.9 & 18.1 & 22.9 & 26.7 \\
\hline
\end{tabular}

\section{How to use materials sustainably}

The environmental effects and cost of standard building materials are generally assessed with a Life Cycle Assessment (LCA). LCA ties in closely with embodied energy of materials in the sense that both consider the concept of the potential environmental and energy inputs from cradle to grave, in other words from production through to use and disposal of a material. LCA is a useful tool that can be used to identify problem areas in the life cycle of a building that have the most impact on the environment. It is also useful to compare different building materials with the same function, for example a steel, timber or concrete frame structure.

One of the most important factors that affect the Life Cycle of a building is the durability of its components. Non-durable building components mostly found in the envelope and finishes of a building result in a high life cycle cost due to repair, maintenance and replacement. The initial cost of a building is generally the determining factor in creating compromise on the choice of building materials by the architect and owners who confuse the initial cost with the running costs of the building. The biggest culprits are developers who want to make a quick profit on the sale of a newly built building. The preoccupation of developers with initial profit becomes apparent when looking at the building life cycle. Little thought is put into the quality or use of the building a few decades down the line.

Differential durability occurs where there is a significant difference in the life span of various components, materials and systems in a building.

Cheap finishes, services and envelope in buildings contribute to raised costs over the life span of such a building that increases with the age of the building. As seen in Figure 1, most of the embodied energy in a building is derived from maintenance and refurbishment of the envelope, finishes and services. With careful design the running costs of a building can be greatly reduced, making it viable for a much longer period of time. One such design strategy is to design details that protect weaker materials from premature damage.

For the sake of sustainability some people compromise on building materials and use highly renewable resources to the detriment of the building life span, affecting the interim maintenance of the building. It is generally observed that building materials with low embodied energy require continuous maintenance and lack durability. Building materials with low embodied energy such as Straw bale also lack structural properties and cannot be efficiently used in high-rise 
constructions. It is therefore important that care is taken with the choice of finishes when considering the life span of a building. A building of high durability should be fitted accordingly and designed for a variety of users over its life span.

To reduce the embodied energy of a building over its life span architects need to understand the environmental impacts of all the aspects of a building such as the transportation costs of building materials, and the ease with which building components can be disassembled for refurbishment and recycling. Designs need to minimise energy usage by employing passive systems for heating, cooling, lighting and ventilation.

To reduce the impact of raw material extraction, it is suggested that the built environment looks into using salvaged material, maximize the recycled content of materials, use renewable resources in the extraction of the materials, use nontoxic constituents, and minimize the environmental impact of activities such as strip mining and dredging. When avoiding high embodied energy materials care should be taken not to create differential durability in the finished product. A building that is expected to last more than 50 years should receive finishes that have a similar degree of durability.

The location of the conversion site should be as close to the source of the raw material or to the end-user to reduce the transport expenses associated with the relocation of materials. The reduction of waste is essential and a closed-loop material use is ideal where recovered materials are the raw materials for new products. The building industry is guilty of being very wasteful with practices such as chasing in conduits and pipes when careful planning and supervision could reduce such practices. This in turn relies upon the architect and contractor to do proper site supervision to ensure more sustainable practices.

The building operation costs can be largely reduced by careful initial planning and use of climatically appropriate orientation and materials. Areas with high diurnal ranges will benefit from building materials with high thermal mass (such as heavyweight concrete, brick or stone) where in moderate climates more lightweight structures (steel or timber) will be more appropriate. Creating thermal comfort is therefore less dependant on air conditioning and HVAC (Heating, Ventilation and Air Conditioning) systems.

Using materials of similar durability throughout the building will reduce the need for refurbishment and repairs of the building. Refurbishment costs can be eliminated by using structural elements as finishes. Large shopping centres in South Africa tend to irresponsibly refurbish when the existing finishes are still of good quality and need just minor repairs. These commercial places should be held more accountable for the expenses they incur on behalf of the environment in order to "attract' consumers to "new" places to shop. In the first world the trend is to initiate sustainable building guidelines such as LEED (Leadership in Energy and Environmental Design) and BREEAM (Building Research Establishment Environmental Assessment Method). Developing countries need to follow suit to reduce the negative impact on the health of the planet.

The use of renewable energy in the production of materials becomes problematic when considering the current cost of different technologies. The 
inefficient use of fossil fuels is still financially much cheaper for creating a constant source of energy than to rely on renewable energies that are relatively unpredictable and needs storage in the form of batteries that in itself is damaging to the environment.

The pitfalls associated with designing for sustainability lie in the consumer's willingness to compromise on products' modularization, using recycled parts that are not as high in quality as new products and the time associated with waiting for the required recycled materials to become available.

\section{Conclusion}

Where sustainability is a driving force, the understanding of the embodied energy of materials used in architecture will lead to sustainable decisions rather than decisions based on fashion and profit.

Cement, aluminium and steel production consumes a large amount of nonrenewable energy and these materials should be used with care when constructing a building. The use of materials of similar durability (such a concrete with aluminium window frames in stead of concrete with biodegradable window frames) reduces the expensive need for refurbishment later during the building's lifespan. The global drive towards sustainability is bringing about legislation to enforce the sustainability of the environment. If a building is designed for-renewable energy use it will reduce the production of greenhouse gases. Vernacular architecture might be exemplary in its use of low-embodied energy materials, but those materials are generally not very durable compared to materials such as concrete and aluminium. The inert strength of low embodied energy materials is generally not comparable with those used in high-rise buildings. One can thus say that there is a continuous satisficing (using the first or most convenient solution to a problem rather than the optimal solution) when it comes to the choice of building material. On the one hand, people want to reduce the impact on their environment, but on the other hand, a regression of technology or increase in financial outlay will not be acceptable.

Aluminium and steel are highly recyclable and should be used in ways that provide for ease of disassembly and recycling. Transporting steel produces a large amount of $\mathrm{CO}_{2}$ and should only be used in districts from where it is readily available. Methods for reducing embodied energy in a building include using of locally available materials of similar durability, designing the building for low maintenance and flexibility in use, and making climatically appropriate decisions on the building's design.

To create a better quality of life it is important to consider the footprint left behind by industry.

\section{References}

[1] Catalli, V. and Williams, M. Designing for Disassembly. Canadian Architect, January 2001. http://cdnarchitect.com/issues/. 2001. 
[2] Centre for building performance research. Victoria University of Wellington. www.vuw.ac.nz/cbpr/documents/pdfs/ee-coefficients.pdf. 2004.

[3] Cole, R.J. \& Kernan, P.C., Life-Cycle Energy Use in Office Buildings. Building and Environment, 31(4), pp 307-317. 1996

[4] Corus Construction Centre. Achieving Sustainable design. http://www.corusconstruction.com/en/responsibility/sustainability/downlo ads/

[5] Corus Construction Centre. Environmental designs in steel. http://www.corusconstruction.com/en/responsibility/sustainability/

[6] CSIRO manufacturing \& infrastructure technology. http://www.cmit.csiro.au/brochures/tech/embodied.

[7] International Aluminium Institute. Aluminium's Life Cycle. http://www.world-aluminium.org/environment/lifecycle/lifecycle1.html. 2000.

[8] Kesik, T. Measures of Sustainability. Architectural Science Forum. Canadian Architect. http://www.cdnarchitect.com/asf/perspectives_sustainibility/measures_of sustainablity/measures_of_sustainablity_embodied.htm.

[9] Portland Cement Association. Concrete thinking for a sustainable world. http://www.cement.org/concretethinking/manu_facts.asp. 2006.

[10] International Aluminium Institute. http://www.world-aluminium.org/ environment/lifecycle/lifecycle1.html. 